\title{
POLÍTICA NACIONAL DE MEDICAMENTOS GENÉRICOS: 21 ANOS NO BRASIL
}

Kamila Pina da Silva ${ }^{1}$, Sara Lira Rodrigues ${ }^{1}$, Orenzio Soler ${ }^{1}$

${ }^{1}$ Universidade Federal do Pará

E-mail para correspondência: soler@gmail.com

Submetido em: 20/04/2020 e aprovado em: 23/06/2020

\section{RESUMO}

Introdução: A Política Nacional de Medicamentos Genéricos no Brasil é uma das estratégias para regular o mercado farmacêutico, aumentar a competitividade de preços e melhorar o acesso aos medicamentos. Fundamenta-se na compreensão de que o acesso universal à saúde é tarefa a ser desempenhada pelo Estado, com a implementação de mecanismos que garantam à população o acesso a medicamentos seguros, com qualidade e preços justos. Objetivos: Buscar evidências de que a Política Nacional de Medicamentos Genéricos no Brasil contribuiu para a melhoria do acesso aos medicamentos, promoveu inovação tecnológica e proporcionou melhorias da economia no setor da indústria farmacêutica. Métodos: Revisão sistemática e síntese narrativa. Resultados e discussão: A Política Nacional de Medicamentos Genéricos no Brasil apresenta evidências da sua contribuição para a melhoria do acesso aos medicamentos, de inovação tecnológica e de melhorias econômicas no setor da indústria farmacêutica. Conclusões: A Política Nacional de Medicamentos Genéricos no Brasil possibilitou maior acesso da população brasileira aos medicamentos; principalmente aquela de baixa e média renda, proporcionando, também, inovação tecnológica, crescimento do mercado farmacêutico e visibilidade internacional.

Palavras-chave: Revisão Sistemática, Políticas Públicas, Indústria Farmacêutica, Política de Medicamentos, Medicamentos Genéricos.

\begin{abstract}
Introduction: The National Policy on Generic Medicines in Brazil is one of the strategies to regulate the pharmaceutical market, increase price competitiveness and improve access to medicines. It is based on the understanding that universal access to health is a task to be performed by the State, with the implementation of mechanisms that guarantee the population access to safe medicines, with quality and fair prices. Aims: To seek evidence that the National Policy on Generic Medicines in Brazil contributed to improving access to medicines, promoted technological innovation and provided improvements in the economy in the pharmaceutical
\end{abstract}


industry sector. Methods: Systematic review and narrative synthesis. Results and discussion: The National Policy on Generic Medicines in Brazil presents evidence of its contribution to improving access to medicines, technological innovation and economic improvements in the pharmaceutical industry sector. Conclusions: The National Policy on Generic Medicines in Brazil allowed greater access of the Brazilian population to medicines; mainly that of low and medium income, also providing technological innovation, growth of the pharmaceutical market and international visibility.

Keywords: Systematic Review, Public policy, Pharmaceutical industry, Medicines Policy, Generic Medicines.

\section{INTRODUÇÃO}

As políticas públicas são objetos de estudo que proporcionam a identificação de diferentes atores e forças políticas. Trata-se de programa de ação governamental que resulta de um processo ou conjunto de processos juridicamente regulados, visando coordenar os meios à disposição do Estado e as atividades privadas, para a realização de objetivos socialmente relevantes e politicamente determinados ${ }^{(1)}$. Políticas públicas são a tradução de planos de governo em programas e ações, servindo como desígnio para várias coisas; dentre elas, a doutrina do direito e da moral, a teoria do Estado, a arte ou a ciência do governo, e como o estudo dos comportamentos intersubjetivos ${ }^{(2)}$.

Políticas públicas é compreendida como um conjunto de programas ou ações governamentais necessárias e suficientes, integradas e articuladas para a provisão de bens ou serviços à sociedade, financiadas por recursos orçamentários ou por benefícios de natureza tributária, creditícia e financeira. Políticas firmam os direitos assegurados constitucionalmente e acontecem nas mais diversas áreas; tais como, saúde, moradia, lazer, educação, cultura, segurança, transporte e assistência social ${ }^{(3)}$.

A avaliação de políticas públicas, executada como um processo sistemático, integrado e institucionalizado, tem como premissa básica verificar a eficiência dos recursos públicos e, quando necessário, identificar possibilidades de aperfeiçoamento da ação estatal, com vistas à melhoria dos processos, dos resultados e da gestão ${ }^{(3)}$.

Ao longo das últimas décadas, um número crescente de estudos tem sido desenvolvido com base na análise de política. Trata-se de um campo de pesquisa relativamente consolidado no exterior e, cada vez mais, também no Brasil. A análise de política busca entender o porquê e para quem aquela política foi elaborada, e não só olhar o conteúdo da política pública em si ${ }^{(4)}$. 
Os estudos desenvolvidos utilizam em sua maioria o método do ciclo de política como instrumento para analisar a política ${ }^{(5)}$.

É importante destacar a diferença entre análise de política e avaliação de política. A avaliação se fundamenta na apreciação dos resultados da política, atentando para categorias como eficácia, efetividade e eficiência; derivados da comparação entre metas e $\operatorname{resultados}^{(5)}$. Já a análise se preocupa com o processo de construção da política pública; principalmente, no que se refere à definição da agenda governamental ${ }^{(5)}$.

Sabe-se, que no início da década de 1990, foram desencadeados esforços para a efetivação do Sistema Único de Saúde (SUS), tendo como orientação os princípios estabelecidos na Constituição Federal de 1988. A Lei Orgânica de Saúde nº 8.080, de 19 de setembro de 1990, assegurou entre os campos de atuação do SUS a execução de ações de assistência terapêutica integral, incluindo a farmacêutica e a formulação da política de medicamentos ${ }^{(6)}$.

A Política Nacional de Medicamentos (PNM), como parte essencial da Política Nacional de Saúde (PNS), foi regulamentada por meio da Portaria n ${ }^{\circ} 3.916$, de 30 de outubro de 1998, visando aumentar o acesso da população a medicamentos com qualidade, segurança, eficácia e ao menor custo possível. Constitui um dos elementos fundamentais para a efetiva implementação de ações capazes de promover a melhoria das condições da assistência à saúde da população ${ }^{(7)}$.

Na perspectiva de aprimorar o Sistema Único de Saúde (SUS), o Conselho Nacional de Saúde (CNS) aprovou por meio da Resolução CNS nº 338, de 06 de maio de 2004, a Política Nacional de Assistência Farmacêutica (PNAF), compreendida como um conjunto de ações voltadas à promoção, proteção e recuperação da saúde, tanto individual como coletiva, tendo o medicamento como insumo essencial e visando o acesso e seu uso racional ${ }^{(8)}$.

A Política Nacional de Assistência Farmacêutica (PNAF) engloba a pesquisa, o desenvolvimento e a produção de medicamentos e insumos, bem como a sua seleção, programação, aquisição, distribuição, dispensação, garantia da qualidade dos produtos e serviços, acompanhamento e avaliação de sua utilização, na perspectiva da obtenção de resultados concretos e da melhoria da qualidade de vida da população ${ }^{(8)}$.

Para assegurar a qualidade e segurança dos medicamentos no Brasil, a Lei $n^{\circ}$ 9.782, de 26 de janeiro de 1999, regulamentou a Agência Nacional de Vigilância Sanitária (ANVISA), órgão essencial na normalização, fiscalização e controle de vigilância sanitária em nível nacional $^{(9)}$. 
A Lei $\mathrm{n}^{\circ}$ 9.787, de 10 de fevereiro de 1999, regulamenta a estratégia de medicamentos genéricos, com o propósito de regular o mercado farmacêutico, aumentar a competitividade de preços e melhorar o acesso aos medicamentos ${ }^{(10)}$. Esta política introduz conceitos nunca antes empregados para o registro de um medicamento, como por exemplo, a equivalência farmacêutica (comprovada por ensaios in vitro) e a bioequivalência (comprovada por ensaios in vivo), estabelecendo um novo padrão para o desenvolvimento e o registro de medicamentos no Brasil ${ }^{(6)}$. O Medicamento Genérico é definido como aquele que é produzido livremente após o prazo de proteção da patente do produto de referência, devendo ser semelhante ao de referência em bioequivalência, a fim de obter o mesmo efeito terapêutico ${ }^{(10)}$.

Neste contexto, este artigo sintetiza evidências de que a Política Nacional de Medicamentos Genéricos no Brasil contribuiu para a melhoria do acesso aos medicamentos, promoveu inovação tecnológica e proporcionou melhorias da economia no setor da indústria farmacêutica.

\section{MÉTODOS}

Trata-se de uma Revisão Sistemática; ou seja, um método de síntese de evidências que avalia criticamente e interpreta todas as pesquisas relevantes disponíveis para uma questão particular, área do conhecimento ou fenômeno de interesse. Por se tratar de método explícito e sistemático para identificar, selecionar e avaliar a qualidade de evidências, as revisões sistemáticas são tipos de estudos produzidos por uma metodologia confiável, rigorosa e auditável $^{(11)}$.

A pergunta que guiou a estratégia de busca indaga se há evidências de que que a Política Nacional de Medicamentos Genéricos no Brasil contribuiu para a melhoria do acesso aos medicamentos, promoveu inovação tecnológica e proporcionou melhorias da economia no setor da indústria farmacêutica. Utilizou-se do acrônimo PICO para se estabelecer os critérios de inclusão: População: População infantil, jovem e adulta; Intervenção: $\mathrm{O}$ uso de medicamentos genéricos; Controle: O uso de medicamentos inovadores e similares; Desfecho: Evidências clínicas, epidemiológicas, humanísticas e econômicas ${ }^{(12)}$. Os critérios de exclusão foram, o tipo de estudo (desenho), tipo de publicação e tipo de desfecho que não atendiam ao acrônimo PICO.

Como desfechos primários buscou-se evidências sobre o desenvolvimento da indústria farmacêutica nacional, aprimoramento de infraestrutura de aparatos tecnológicos de apoio à indústria farmacêutica nacional, pesquisas e inovação tecnológica. Como desfechos secundários buscou-se evidências sobre a melhoria do acesso aos medicamentos, aumento da 
venda, do lucro e da disponibilidade de medicamentos e custo dos medicamentos genéricos ${ }^{(12,}$ 13).

Abrangeu estudos publicados nas bases Cochrane Library, Epistemonikos, Health Evidence, Health Systems Evidence, National Center for Biotechnology Information, Biblioteca Virtual de Saúde e Google Scholar. Não houve restrição de tempo e de idioma. A estratégia de busca incluiu Medical Subject Headings (MeSH) e Descritores em Ciências da Saúde (DeCS), utilizando-se os domínios "Generic Drugs Policy in Brazil” OR "Generic Medicine Policy in Brazil" como condição do estudo. Foram utilizadas os seguintes unitermos: ("Generic drugs policy in Brazil” OR “Generic medicine policy in Brazil”) AND (“Generic drugs" OR "Generic medicine”) AND (“Analysis”) AND (“Evaluation”) AND (Systematic review* OR Metaanalyses* OR Economic evaluation*). Dados e informações complementares foram retirados dos sítios da Federação Brasileira das Redes Associativistas e Independentes de Farmácias (Febrafar) e da Associação Brasileira das Indústrias de Medicamentos Genéricos (ProGenéricos).

A triagem dos títulos e resumos recuperados foram selecionados de forma independente por três autores, respeitando-se os critérios de inclusão. Quaisquer incertezas ou desentendimentos remanescentes foram resolvidos por consenso através do diálogo entre os autores. Os artigos de texto completo foram recuperados, os dados extraídos e a qualidade dos artigos avaliada (Figura 1).

O Mendeley Desktop ${ }^{\circledR}$ foi utilizado como gerenciador de referências ${ }^{(14)}$. A Plataforma Rayyan $^{\circledR}$ foi utilizada para fazer a triagem e seleção dos artigos ${ }^{(15)}$. O Prisma Flow Diagram ${ }^{\circledR}$ foi utilizado para descrever o fluxo de informações através das diferentes fases da revisão sistemática $^{(16)}$. O PROGRESS ${ }^{\circledR}$ foi utilizado para identificar determinantes sociais e de equidade $^{(17)}$. Uma planilha Excel $^{\circledR}$ foi utilizada para organizar dados e informações do artigo; tais como: Nome do artigo; Nome dos autores; Revista e ano de publicação; Objetivo do estudo; Desenho ou método do estudo; Métodos estatísticos utilizados; Tipos de intervenções avaliadas; Resultados (desfechos); Avaliação da qualidade do artigo; Identificação de Vieses; Inclusão de países de alta, média e baixa renda; em especial o Brasil; Determinantes sociais e de equidade; Conclusão e contribuição do estudo; Uso de referências atualizadas; Lacunas e limitações do estudo; Perguntas não respondidas pelos autores; Conflitos de interesse, facilitando, assim a síntese narrativa. 
Figura 1 - Fluxograma do processo de seleção dos artigos incluídos na revisão

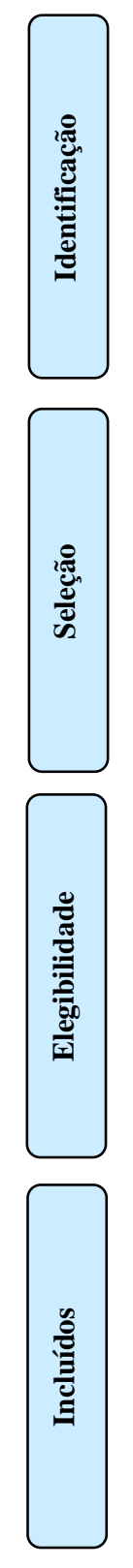
Artigos identificados por meio de pesquisa nos bancos de dados Cochrane Library, Epistemonikos, Health Evidence, Health Systems Evidence, National Center for Biotechnology Information, Biblioteca Virtual de Saúde e Google Scholar: $(\mathbf{n}=\mathbf{2 0 7})$ $(\mathbf{n}=\mathbf{2 6})$

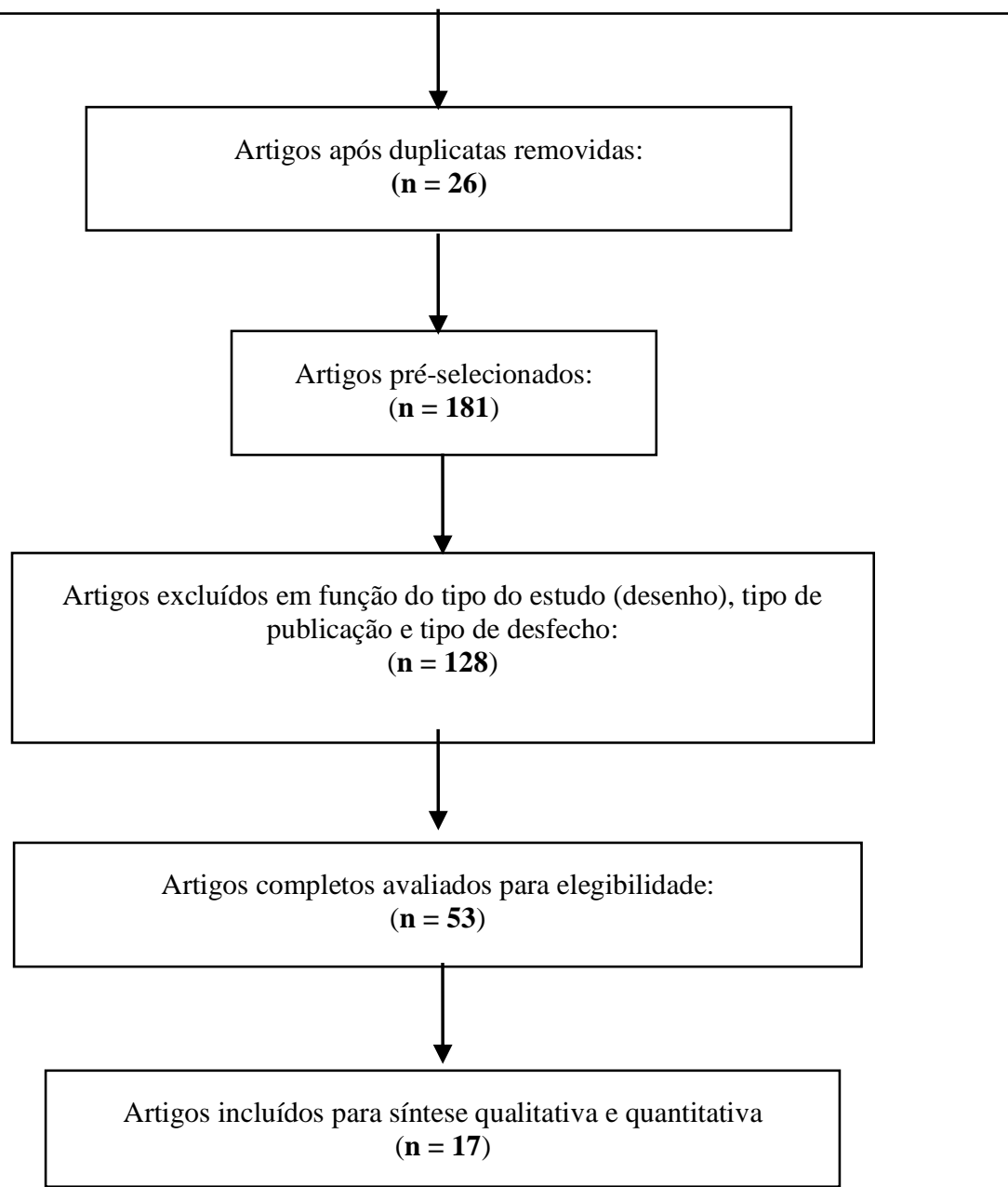

Adaptado de Moher et al. 2009 ${ }^{(16)}$. Informações complementares: www.prisma-statement.org

A qualidade dos estudos foi avaliada utilizando-se as ferramentas Avaliação da Qualidade de Revisões Sistemáticas ${ }^{(18)}$; Avaliação da Qualidade de Revisões Integrativas ${ }^{(19)}$; Avaliação da Qualidade de Estudo Transversal ${ }^{(20)}$; Avaliação da Qualidade de Estudos de Coorte ${ }^{(21)}$ e Avaliação Econômica de Tecnologias em Saúde ${ }^{(22)}$.

Como material suplementar, tem-se: (1) Estratégias de busca, (2) Termos e definições relacionadas aos medicamentos genéricos, (3) Relação dos artigos excluídos, (4) Quadros de avaliação da qualidade dos artigos selecionados, (5) Perfil e características dos artigos 
selecionados, (6) Determinantes sociais e de equidade (PROGRESS ${ }^{\circledR}$ ). Para ter acesso ao material suplementar, favor entrar em contato com os autores.

De acordo com a Resolução do CNS n 466 de 12 de dezembro de $2012^{(23)}$ e da Resolução $\mathrm{n}^{\text {o }} 510$, de 07 de abril de $2016^{(24)}$ não foi necessário o registro no Sistema Nacional de Informação sobre Ética em Pesquisa envolvendo Seres Humanos (SISNEP) via Plataforma Brasil.

\section{RESULTADOS E DISCUSSÃO}

Foram selecionados 207 artigos científicos, dos quais 26 foram excluídos por caracterizarem duplicatas e 181 foram excluídos após leitura dos títulos e/ou resumos. Dos 128 artigos pré-selecionados, 53 foram selecionados para análise qualitativa e quantitativa (Figura 1). A Tabela 1 apresenta o perfil dos 17 estudos incluídos na revisão sistemática.

Tabela 1 - Perfil dos artigos selecionados (Continua)

\begin{tabular}{|c|c|c|c|}
\hline ARTIGO & OBJETIVO & MÉTODO & CONCLUSÃO \\
\hline $\begin{array}{l}\text { Mishuk et al. } \\
(2018)^{(25)}\end{array}$ & $\begin{array}{l}\text { Avaliar as evidências da } \\
\text { associação entre as características } \\
\text { dos pacientes e o uso de } \\
\text { medicamentos genéricos, a fim de } \\
\text { informar o desenvolvimento do } \\
\text { alcance educacional para melhorar } \\
\text { o uso de medicamentos genéricos } \\
\text { entre os pacientes. }\end{array}$ & $\begin{array}{l}\text { Revisão } \\
\text { sistemática. }\end{array}$ & $\begin{array}{l}\text { Pacientes com menor renda foram mais } \\
\text { propensos a usar medicamentos genéricos, } \\
\text { enquanto as evidências foram heterogêneas em } \\
\text { relação à associação entre uso de medicamentos } \\
\text { genéricos e sexo, idade ou raça/etnia. O alcance } \\
\text { educacional direcionado a pacientes com renda } \\
\text { mais alta para entender suas perspectivas em } \\
\text { medicamentos genéricos pode ajudar a melhorar } \\
\text { o uso de medicamentos genéricos nessa } \\
\text { população. }\end{array}$ \\
\hline $\begin{array}{l}\text { Manhães e } \\
\text { Hasenclever } \\
(2018)^{(26)}\end{array}$ & $\begin{array}{l}\text { Caracterizar a dinâmica territorial } \\
\text { da indústria farmacêutica } \\
\text { decorrente da política pública dos } \\
\text { medicamentos genéricos no Brasil } \\
\text { no período entre } 2000 \text { e } 2017 \text {. }\end{array}$ & $\begin{array}{l}\text { Revisão } \\
\text { Integrativa. }\end{array}$ & $\begin{array}{l}\text { Os principais resultados mostram que a } \\
\text { produção de genéricos cresceu } \\
\text { significativamente no período referido, } \\
\text { fortalecendo a indústria farmacêutica de capital } \\
\text { nacional e promovendo desconcentração relativa } \\
\text { aos grandes centros de São Paulo e Rio de } \\
\text { Janeiro. }\end{array}$ \\
\hline $\begin{array}{l}\text { Guttier et al. } \\
(2017)^{(27)}\end{array}$ & $\begin{array}{l}\text { Investigar intervenções voltadas à } \\
\text { promoção do uso dos } \\
\text { medicamentos genéricos e seus } \\
\text { impactos. }\end{array}$ & $\begin{array}{l}\text { Revisão } \\
\text { Sistemática. }\end{array}$ & $\begin{array}{l}\text { As intervenções utilizadas foram educativas, de } \\
\text { incentivo financeiro, uso de prescrição } \\
\text { eletrônica e gerencial. Intervenções aplicadas } \\
\text { aos prescritores tiveram impacto pequeno a } \\
\text { médio, com qualidade muito baixa a baixa; aos } \\
\text { farmacêuticos, impacto pequeno e qualidade } \\
\text { muito baixa; aos usuários mostraram impacto } \\
\text { médio e grande com qualidade muito baixa e } \\
\text { baixa. São necessários mais estudos de boa } \\
\text { qualidade abordando as intervenções. }\end{array}$ \\
\hline $\begin{array}{l}\text { Luiza et } \\
(2017)^{(28)}\end{array}$ & $\begin{array}{l}\text { Disponibilizar uma visão geral do } \\
\text { mercado farmacêutico, incluindo } \\
\text { produção local e fabricação de } \\
\text { ingredientes farmacêuticos ativos } \\
\text { e formas farmacêuticas acabadas. }\end{array}$ & $\begin{array}{l}\text { Revisão } \\
\text { sistemática }\end{array}$ & $\begin{array}{l}\text { E fornecida uma visão geral do mercado } \\
\text { farmacêutico, incluindo produção local e } \\
\text { fabricação de ingredientes farmacêuticos ativos } \\
\text { e formas farmacêuticas acabadas. O "Complexo } \\
\text { Industrial da Saúde" como um compromisso } \\
\text { político que liga as necessidades do sistema de } \\
\text { saúde às políticas industriais é brevemente } \\
\text { descrito. }\end{array}$ \\
\hline
\end{tabular}


Tabela 1 - Perfil dos artigos selecionados (Continua)

\begin{tabular}{|c|c|c|c|}
\hline $\begin{array}{l}\text { Fonseca } \\
\text { Shadlen } \\
(2017)(29)\end{array}$ & $\begin{array}{l}\text { Examinar como os diversos } \\
\text { interesses das partes interessadas } \\
\text { dos setores público e privado } \\
\text { podem moldar a política de } \\
\text { medicamentos genéricos e sua } \\
\text { implementação. }\end{array}$ & $\begin{array}{l}\text { Estudo } \\
\text { transversal. }\end{array}$ & $\begin{array}{l}\text { Essa análise chama a atenção para as várias } \\
\text { dimensões da regulamentação nacional sobre } \\
\text { medicamentos genéricos e seus principais } \\
\text { instrumentos políticos; contribui com a } \\
\text { literatura, criando novas evidências conceituais } \\
\text { e empíricas sobre a conformidade dos países em } \\
\text { desenvolvimento com as diretrizes de } \\
\text { medicamentos genéricos. Para entender as } \\
\text { diferenças regionais e as opções regulatórias, é } \\
\text { preciso esclarecer os incentivos e os interesses } \\
\text { de saúde pública desses instrumentos e as } \\
\text { oportunidades institucionais de marketing. }\end{array}$ \\
\hline $\begin{array}{l}\text { Barbosa e Silva } \\
(2017)(30)\end{array}$ & $\begin{array}{l}\text { Documentar a padrão de entrada } \\
\text { de fornecedores de medicamentos } \\
\text { genéricos no Brasil após a chegada } \\
\text { do primeiro fabricante de } \\
\text { medicamento genérico } \\
\text { no mercado interno. }\end{array}$ & $\begin{array}{l}\text { Estudo } \\
\text { transversal. }\end{array}$ & $\begin{array}{l}\text { Verificou-se que houve uma entrada contínua de } \\
\text { fabricantes de genéricos após o primeiro } \\
\text { genérico entrar no mercado brasileiro. No } \\
\text { entanto, esse aumento de produtores diminui ao } \\
\text { longo do tempo em função da concorrência. } \\
\text { Conclui-se que houve uma maior concentração } \\
\text { de } \\
\text { fabricantes de genéricos nos primeiros anos, } \\
\text { diminuindo ao longo do tempo. }\end{array}$ \\
\hline $\begin{array}{l}\text { Vasconcelos et } \\
\text { al. }(2017)^{(31)}\end{array}$ & $\begin{array}{l}\text { Fazer um balanço dos } 20 \text { anos da } \\
\text { Política Nacional de } \\
\text { Medicamentos e analisando } \\
\text { diretrizes específicas à luz de } \\
\text { princípios do SUS. }\end{array}$ & $\begin{array}{l}\text { Estudo } \\
\text { transversal. }\end{array}$ & $\begin{array}{l}\text { Houve forte produção normativa sobre os } \\
\text { requisitos e os procedimentos para concessão e } \\
\text { renovação de registro de medicamentos no País, } \\
\text { especialmente a introdução dos genéricos - } \\
\text { critério garantidor de menor incerteza quanto à } \\
\text { eficácia e segurança dos medicamentos } \\
\text { presentes no mercado brasileiro e estratégia de } \\
\text { estímulo à concorrência. }\end{array}$ \\
\hline $\begin{array}{l}\text { Lira et } \\
(2014)^{(32)}\end{array}$ & $\begin{array}{l}\text { Avaliar o nível de conhecimento, } \\
\text { percepções e uso } \\
\text { perfil de medicamentos genéricos } \\
\text { entre leigos. }\end{array}$ & $\begin{array}{l}\text { Estudo } \\
\text { transversal. }\end{array}$ & $\begin{array}{l}\text { Para um público leigo, a amostra estudada } \\
\text { apresentou suficiente conhecimento com relação } \\
\text { aos genéricos, no que concerne à definição, } \\
\text { eficácia e custo. Dessa forma, os voluntários } \\
\text { entrevistados apresentaram elevada propensão à } \\
\text { utilização de genéricos. Adicionalmente, os } \\
\text { resultados deste estudo demonstraram que se faz } \\
\text { necessário implantar programas para aumentar a } \\
\text { prescrição de medicamentos genéricos por } \\
\text { profissionais médicos. }\end{array}$ \\
\hline $\begin{array}{l}\text { Caliari e Ruiz } \\
(2014)^{(33)}\end{array}$ & $\begin{array}{l}\text { Avaliar os impactos da política de } \\
\text { medicamentos genéricos, } \\
\text { relacionando-os com a escala de } \\
\text { negócios e inovação. }\end{array}$ & $\begin{array}{l}\text { Estudo } \\
\text { transversal. }\end{array}$ & $\begin{array}{l}\text { Demostram um grande aumento na participação } \\
\text { de mercado em favor das empresas domésticas, } \\
\text { mas apenas um pequeno aumento nos gastos e } \\
\text { inovação em P\&D e inovação nessas empresas. } \\
\text { Esse aumento na escala de negócios representou } \\
\text { uma janela de oportunidade para as empresas } \\
\text { nacionais, mas as recentes fusões e aquisições de } \\
\text { empresas estrangeiras desafiaram sua posção. A } \\
\text { fraca competitividade das empresas domésticas } \\
\text { decorre de suas fracas capacidades tecnológicas, } \\
\text { que são o resultado de uma política industrial de } \\
\text { 'demanda puxada' sem o apoio de uma política } \\
\text { industrial 'tecnológica'. }\end{array}$ \\
\hline $\begin{array}{l}\text { Kaplan et al. } \\
(2012)^{(34)}\end{array}$ & $\begin{array}{l}\text { Revisar a literatura sobre o } \\
\text { impacto das políticas projetadas } \\
\text { para aumentar a captação de } \\
\text { medicamentos genéricos nos } \\
\text { países de baixa e média renda. }\end{array}$ & $\begin{array}{l}\text { Revisão } \\
\text { integrativa. }\end{array}$ & $\begin{array}{l}\text { Há pouca avaliação de políticas para determinar } \\
\text { quais políticas pró-genéricas aumentam a } \\
\text { utilização de medicamentos genéricos nos países } \\
\text { de baixa e média renda. Garantir uma autoridade } \\
\text { reguladora de medicamentos em funcionamento, } \\
\text { criar um mercado razoavelmente robusto de } \\
\text { medicamentos genéricos e alinhar incentivos } \\
\text { para médicos, consumidores e vendedores de } \\
\text { medicamentos são pré-requisitos necessários } \\
\text { para aumentar a captação e uso de medicamentos } \\
\text { genéricos. }\end{array}$ \\
\hline
\end{tabular}


Tabela 1 - Perfil dos artigos selecionados (Continua)

\begin{tabular}{|c|c|c|c|}
\hline $\begin{array}{l}\text { Araújo et al. } \\
(2010)(35)\end{array}$ & $\begin{array}{l}\text { Apresentar a definição de } \\
\text { conceitos no contexto das leis } \\
\text { brasileiras e oferece uma } \\
\text { descrição histórica e cronológica } \\
\text { da implementação da política de } \\
\text { genéricos no Brasil, listando ainda } \\
\text { as resoluções que atualmente estão } \\
\text { em vigor. }\end{array}$ & $\begin{array}{l}\text { Revisão } \\
\text { integrativa. }\end{array}$ & $\begin{array}{l}\text { Por meio da avaliação das resoluções publicadas } \\
\text { pela ANVISA até o momento, verifica-se que } \\
\text { houve várias alterações, ao longo do tempo, no } \\
\text { sentido de otimizar a implementação da política } \\
\text { de medicamentos genéricos e viabilizar o } \\
\text { processo de adequação dos medicamentos } \\
\text { similares no Brasil, o que representou grande } \\
\text { avanço técnico-científico para o País. }\end{array}$ \\
\hline $\begin{array}{l}\text { Soares et al. } \\
(2012)(36)\end{array}$ & $\begin{array}{l}\text { Calcular os prazos para obtenção } \\
\text { de registro de medicamentos } \\
\text { genéricos e os principais pontos } \\
\text { envolvidos no ganho ou na perda } \\
\text { de eficiência neste processo. }\end{array}$ & $\begin{array}{l}\text { Estudo } \\
\text { transversal. }\end{array}$ & $\begin{array}{l}\text { A promulgação da lei e a criação da Anvisa } \\
\text { representaram uma mudança significativa na } \\
\text { política governamental sobre este segmento e } \\
\text { causaram grande impacto na estrutura do } \\
\text { mercado farmacêutico brasileiro. Com a } \\
\text { implementação da política de genéricos, o } \\
\text { mercado, que até então era dominado por } \\
\text { empresas multinacionais, começou a oferecer } \\
\text { espaço para o crescimento das indústrias } \\
\text { nacionais. Estas indústrias passaram a investir } \\
\text { pesadamente no setor e alavancaram um } \\
\text { crescimento significativo do mercado. }\end{array}$ \\
\hline $\begin{array}{l}\text { Fiuza } \\
\text { Caballero } \\
(2010)^{(37)}\end{array}$ & $\begin{array}{l}\text { Estimar a entrada de versões } \\
\text { genéricas de medicamentos fora } \\
\text { de patente nas várias classes } \\
\text { terapêuticas, usando tanto } \\
\text { modelos de dados de contagem } \\
\text { como multinomiais ordenados. }\end{array}$ & $\begin{array}{l}\text { Estudo } \\
\text { transversal. }\end{array}$ & $\begin{array}{l}\text { Registram que mudanças na legislação brasileira } \\
\text { durante os anos } 1990 \text { e a Lei dos Genéricos em } \\
1999 \text {, contribuíram para a substituição de } \\
\text { medicamentos de referência por genéricos no } \\
\text { mercado nacional. Em adição, os autores } \\
\text { inferem que a entrada de versões genéricas de } \\
\text { medicamentos pioneiros já sem patente nas } \\
\text { várias classes terapêuticas, contribuíram para a } \\
\text { retomada de controles de preços na virada do } \\
\text { século. }\end{array}$ \\
\hline $\begin{array}{l}\text { Quental et al. } \\
(2008)^{(38)}\end{array}$ & $\begin{array}{l}\text { Apresentar o caso dos } \\
\text { medicamentos genéricos como } \\
\text { uma experiência de sucesso na } \\
\text { integração das políticas sociais } \\
\text { voltadas para um maior acesso da } \\
\text { população a medicamentos e a } \\
\text { medicamentos com qualidade } \\
\text { garantida, com as políticas } \\
\text { econômicas voltadas para o } \\
\text { desenvolvimento industrial. }\end{array}$ & $\begin{array}{l}\text { Estudo } \\
\text { transversal. }\end{array}$ & $\begin{array}{l}\text { Em síntese, a política de genéricos se mostrou } \\
\text { acertada, permitiu ganhos estáticos de aumento } \\
\text { da oferta e redução de preços, mas ainda deve } \\
\text { avançar no sentido de sua contribuição para a } \\
\text { superação das duas lacunas centrais do } \\
\text { complexo industrial da saúde: a base empresarial } \\
\text { local de inovação e o comprometimento com as } \\
\text { condições de saúde da população brasileira }\end{array}$ \\
\hline $\begin{array}{l}\text { Dias } \\
\text { Romano- } \\
\text { Lieber } \\
(2006)^{(39)}\end{array}$ & $\begin{array}{l}\text { descrever este processo ocorrido } \\
\text { na época da implantação. Foi } \\
\text { examinada a legislação pertinente } \\
\text { aos medicamentos genéricos no } \\
\text { país, publicada entre } 1999 \text { e } 2002 \text {. }\end{array}$ & $\begin{array}{l}\text { Estudo } \\
\text { transversal. }\end{array}$ & $\begin{array}{l}\text { Em pouco tempo, os genéricos conquistaram } \\
\text { espaço considerável no mercado farmacêutico } \\
\text { brasileiro. A contínua adequação da legislação, } \\
\text { o respaldo da mídia e o envolvimento do } \\
\text { governo em sua divulgação possibilitaram o } \\
\text { sucesso obtido. Não houve aumento } \\
\text { significativo do acesso da população aos } \\
\text { medicamentos, entretanto, passou-se a contar } \\
\text { com a oportunidade de adquirir medicamentos a } \\
\text { preços mais acessíveis e com garantia de } \\
\text { qualidade e intercambiamento. }\end{array}$ \\
\hline $\begin{array}{l}\text { Bermudez } \\
(1994)(41)\end{array}$ & $\begin{array}{l}\text { Analisar as principais } \\
\text { características da indústria } \\
\text { farmacêutica em todo o mundo e } \\
\text { os aspectos do mercado de } \\
\text { essa indústria no Brasil. }\end{array}$ & $\begin{array}{l}\text { Estudo } \\
\text { transversal. }\end{array}$ & $\begin{array}{l}\text { Uma proposta de política de medicamentos } \\
\text { genéricos tem que se constituir em uma ação } \\
\text { setorial, envolvendo outros ministérios e outras } \\
\text { esferas de governo, além da sociedade. Desde } \\
\text { que ela seja assumida com respaldo político } \\
\text { governamental, os pontos a seguir representam } \\
\text { questões que precisam ser equacionadas de } \\
\text { maneira integrada para implantar um programa } \\
\text { deste tipo }\end{array}$ \\
\hline
\end{tabular}


Tabela 1 - Perfil dos artigos selecionados (Final)

\begin{tabular}{|c|c|c|c|}
\hline $\begin{array}{l}\text { Bertoldi, } \\
\text { Barros e Hallal } \\
(2005)^{(40)}\end{array}$ & $\begin{array}{l}\text { Avaliar o conhecimento e } \\
\text { utilização de medicamentos } \\
\text { genéricos em uma amostra } \\
\text { populacional de adultos de uma } \\
\text { cidade no sul do Brasil. }\end{array}$ & Coorte. & $\begin{array}{l}\text { A proporção de genéricos no total de } \\
\text { medicamentos foi de } 3,9 \% \text {. Enquanto } 86,0 \% \\
\text { sabiam que o preço dos genéricos era menor e } \\
70,0 \% \text { que a qualidade era equivalente aos } \\
\text { medicamentos de marca, apenas } 57,0 \% \\
\text { conheciam alguma característica da embalagem } \\
\text { que diferencia os genéricos de outros } \\
\text { medicamentos. A maior proporção de uso de } \\
\text { genéricos foi encontrada no grupo } \\
\text { farmacológico dos antimicrobianos. Um } \\
\text { medicamento de marca (com nome comercial } \\
\text { semelhante ao genérico) foi erroneamente } \\
\text { classificado como genérico através de fotos por } \\
48,0 \% \text { das pessoas. Entre os indivíduos que } \\
\text { compraram medicamentos no período de } 15 \\
\text { dias, } 18,9 \% \text { relataram comprar um genérico, mas } \\
\text { esse resultado deve ser interpretado com cautela, } \\
\text { pois frequentemente a população não consegue } \\
\text { diferenciar os genéricos dos demais } \\
\text { medicamentos. }\end{array}$ \\
\hline
\end{tabular}

Fonte: Análise e avaliação da política nacional de medicamentos genéricos no Brasil, 2019 ${ }^{(42)}$.

Mishuk et al. (2018) ${ }^{(25)}$, Manhães e Hasenclever (2018) ${ }^{(26)}$, Guttier et al. (2017) ${ }^{(27)}$, Luiza et al. (2017) $)^{(28)}$, Fonseca e Shadlen $(2017)^{(29)}$, Barbosa e Silva $(2017)^{(30)}$, Vasconcelos et al. $(2017)^{(31)}$, Lira et al. (2014) ${ }^{(32)}$, Araújo et al. (2010) $)^{(35)}$, Fiuza e Caballero (2010) $)^{(37)}$, Quental et al. (2008) $)^{(38)}$, Dias e Romano-Lieber (2006) $)^{(39)}$, Bertoldi, Barros e Hallal (2005) ${ }^{(40)}$ e Bermudez $(1994)^{(41)}$ apresentam evidências de que a Política Nacional de Medicamentos Genéricos no Brasil contribuiu para a melhoria do acesso aos medicamentos (Quadro 1).

Mishuk et al. (2018) ${ }^{(25)}$, Manhães e Hasenclever (2018) ${ }^{(26)}$, Guttier et al. (2017) ${ }^{(27)}$, Luiza et al. (2017) ${ }^{(28)}$, Fonseca e Shadlen (2017) $)^{(29)}$, Caliari e Ruiz (2014) $)^{(33)}$, Araújo et al. $(2010)^{(35)}$, Soares et al. (2012) ${ }^{(36)}$, Fiuza e Caballero $(2010)^{(37)}$ e Quental et al. (2008) ${ }^{(38)}$ apresentam evidências de que a Política Nacional de Medicamentos Genéricos no Brasil contribuiu para inovações tecnológicas (Quadro 1).

Mishuk et al. (2018) ${ }^{(25)}$, Manhães e Hasenclever (2018) $)^{(26)}$, Guttier et al. (2017) ${ }^{(27)}$, Barbosa e Silva $(2017)^{(30)}$, Caliari e Ruiz $(2014)^{(33)}$, Kaplan et al. (2012) $)^{(34)}$, Araújo et al. $(2010)^{(35)}$, Fiuza e Caballero (2010) ${ }^{(37)}$ e Quental et al. (2008)( ${ }^{38)}$ apresentam evidências de que a Política Nacional de Medicamentos Genéricos no Brasil proporcionou melhorias da economia no setor da indústria farmacêutica (Quadro 1). 
Quadro 1 - Tipos de evidências apresentadas nos estudos selecionados

\begin{tabular}{|c|c|c|c|}
\hline \multirow[b]{2}{*}{ ARTIGO } & \multicolumn{3}{|c|}{ EVIDÊNCIAS } \\
\hline & $\begin{array}{l}\text { Melhoria do } \\
\text { acesso }\end{array}$ & Econômicas & Inovação tecnológica \\
\hline Mishuk et al. $(2018)^{(25)}$ & Sim & Sim & Sim \\
\hline Manhães e Hasenclever (2018) ${ }^{(26)}$ & Sim & Sim & Sim \\
\hline Guttier et al. $(2017)^{(27)}$ & Sim & Sim & Sim \\
\hline Luiza et al. $(2017)^{(28)}$ & Sim & - & Sim \\
\hline Fonseca e Shadlen $(2017)^{(29)}$ & Sim & - & Sim \\
\hline Barbosa e Silva (2017) $)^{(30)}$ & Sim & Sim & - \\
\hline Vasconcelos et al. (2017) ${ }^{(31)}$ & Sim & - & - \\
\hline Lira et al. $(2014)^{(32)}$ & Sim & - & - \\
\hline Caliari e Ruiz (2014) ${ }^{(33)}$ & - & Sim & Sim \\
\hline Kaplan et al. $(2012)^{(34)}$ & - & Sim & - \\
\hline Araújo et al. (2010) $)^{(35)}$ & Sim & Sim & Sim \\
\hline Soares et al. $(2012)^{(36)}$ & - & - & Sim \\
\hline Fiuza e Caballero $(2010)^{(37)}$ & Sim & Sim & Sim \\
\hline Quental et al. $(2008)^{(38)}$ & Sim & Sim & Sim \\
\hline Dias e Romano-Lieber $(2006)^{(39)}$ & Sim & - & \\
\hline Bertoldi, Barros e Hallal (2005) $)^{(40)}$ & Sim & - & - \\
\hline Bermudez $(1994)^{(41)}$ & Sim & - & - \\
\hline
\end{tabular}

Fonte: Análise e avaliação da política nacional de medicamentos genéricos no Brasil, 2019 ${ }^{(42)}$.

Quanto aos determinantes sociais e equidade (Quadro 1), Mishuk et al. (2018) ${ }^{(25)}$ aborda aspectos de Local de residência (P), Raça/etnia/cultura/idioma (R), Sexo/gênero (G) e Estado socioeconômico (S); Guttier et al. (2017) ${ }^{(27)}$ Local de residência (P) e Sexo/gênero (G); Luiza et al. (2017) ${ }^{(28)}$ Local de residência (P) e Sexo/gênero (G); Lira et al. (2014) ${ }^{(32)}$ Local de residência $(P)$, Sexo/gênero $(G)$ e Educação (E); Bertoldi, Barros e Hallal (2005) ${ }^{(40)}$ Local de residência $(P)$, Sexo/gênero $(G)$ e Educação $(E)$.

Já Manhães e Hasenclever (2018)(26), Fonseca e Shadlen $(2017)^{(29)}$, Barbosa e Silva $(2017)^{(30)}$, Vasconcelos et al. (2017) $)^{(31)}$, Caliari e Ruiz (2014) ${ }^{(33)}$, Kaplan et al. (2012) ${ }^{(34)}$, Araújo et al. (2010) ${ }^{(35)}$, Soares et al. (2012) ${ }^{(36)}$, Fiuza e Caballero $(2010)^{(37)}$, Quental et al. $(2008)^{(38)}$, Dias e Romano-Lieber $(2006)^{(39)}$, não abordam determinantes sociais e equidade em seus estudos. 
Quadro 2 - Determinantes sociais e de equidade (PROGRESS)

\begin{tabular}{|c|c|c|c|c|c|c|c|c|}
\hline \multirow{2}{*}{ ARTIGO } & \multicolumn{8}{|c|}{ DETERMINANTES SOCIAIS E DE EQUIDADE } \\
\hline & $\mathbf{P}$ & $\mathbf{R}$ & $\mathbf{O}$ & G & $\mathbf{R}$ & $\mathbf{E}$ & $\mathbf{S}$ & $\mathbf{S}$ \\
\hline Mishuk et al. (2018) $)^{(25)}$ & $(+)$ & $(+)$ & $(-)$ & की & $(-)$ & $(-)$ & $(+)$ & - \\
\hline Manhães e Hasenclever $(2018)^{(26)}$ & $(-)$ & $(-)$ & $(-)$ & $(-)$ & $(-)$ & $(-)$ & $(-)$ & - \\
\hline Guttier et al. $(2017)^{(27)}$ & $(+)$ & $(-)$ & $(-)$ & की & $(-)$ & $(-)$ & $(-)$ & - \\
\hline Luiza et al. $(2017)^{(28)}$ & $(+)$ & $(-)$ & $(-)$ & 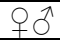 & $(-)$ & $(-)$ & $(-)$ & - \\
\hline Fonseca e Shadlen $(2017)^{(29)}$ & $(-)$ & $(-)$ & $(-)$ & $(-)$ & $(-)$ & $(-)$ & $(-)$ & - \\
\hline Barbosa e Silva $(2017)^{(30)}$ & $(-)$ & $(-)$ & $(-)$ & $(-)$ & $(-)$ & $(-)$ & $(-)$ & - \\
\hline Vasconcelos et al. $(2017)^{(31)}$ & $(-)$ & $(-)$ & $(-)$ & $(-)$ & $(-)$ & $(-)$ & $(-)$ & - \\
\hline Lira et al. $(2014)^{(32)}$ & $(+)$ & $(-)$ & $(-)$ & $90^{\lambda}$ & $(-)$ & $*$ & $(-)$ & - \\
\hline Caliari e Ruiz (2014) ${ }^{(33)}$ & $(-)$ & $(-)$ & $(-)$ & $(-)$ & $(-)$ & $(-)$ & $(-)$ & - \\
\hline Kaplan et al. (2012) ${ }^{(34)}$ & $(-)$ & $(-)$ & $(-)$ & $(-)$ & $(-)$ & $(-)$ & $(-)$ & - \\
\hline Araújo et al. (2010) & $(-)$ & $(-)$ & $(-)$ & $(-)$ & $(-)$ & $(-)$ & $(-)$ & - \\
\hline Soares et al. $(2012)^{(36)}$ & $(-)$ & $(-)$ & $(-)$ & $(-)$ & $(-)$ & $(-)$ & $(-)$ & - \\
\hline Fiuza e Caballero $(2010)^{(37)}$ & $(-)$ & $(-)$ & $(-)$ & $(-)$ & $(-)$ & $(-)$ & $(-)$ & - \\
\hline Quental et al. $(2008)^{(38)}$ & $(-)$ & $(-)$ & $(-)$ & $(-)$ & $(-)$ & $(-)$ & $(-)$ & - \\
\hline Dias e Romano-Lieber $(2006)^{(39)}$ & $(-)$ & $(-)$ & $(-)$ & $(-)$ & $(-)$ & $(-)$ & $(-)$ & - \\
\hline Bertoldi, Barros e Hallal (2005) ${ }^{(40)}$ & $(+)$ & $(-)$ & $(-)$ & की & $(-)$ & $*$ & $(-)$ & - \\
\hline Bermudez $(1994)^{(41)}$ & $(-)$ & $(-)$ & $(-)$ & $(-)$ & $(-)$ & $(-)$ & $(-)$ & - \\
\hline
\end{tabular}

Legenda:

$\mathbf{P}=$ Local de residência; $\mathbf{R}=$ Raça/etnia/cultura/idioma; $\mathbf{O}=$ Ocupação; $\mathbf{G}=$ Sexo/gênero; $\mathbf{R}=$ Religião $; \mathbf{E}=$ Educação; $\mathbf{S}=$ Estado socioeconômico; $\mathbf{S}=$ Capital social. $(+)$ = País de alta, média e baixa renda, sem mencionar se vivem em zona urbana ou rural. ( - ) = Sem informação. $\widehat{\delta}=$ masculino; + = feminino.

* = Educação não formal.

Fonte: Análise e avaliação da política nacional de medicamentos genéricos no Brasil, 2019 ${ }^{(42)}$

No contexto do Regime de Exceção, após o golpe militar de 1964, o governo decidiu fazer um extenso controle de preços, visando controlar a inflação até que esta desaparecesse. Esta política perdurou até 1994, sob a justificativa que se os preços fossem liberados haveria uma explosão inflacionária ${ }^{(43)}$. Política pública relacionada a regulação de medicamentos vem desde a década de 1970, com a promulgação da Lei $\mathrm{n}^{\circ}$ 6.360, de 23 de setembro de $1976,{ }^{(44)}$ a qual dispõe sobre a vigilância sanitária a que ficam sujeitos os medicamentos, as drogas, os insumos farmacêuticos e correlatos, cosméticos, saneantes e outros produtos, entre outras providências.

Nas décadas de 1970 e 1980 as dificuldades de acesso aos medicamentos estava relacionada aos preços da matéria prima, controlados pelo Conselho Interministerial de Preços (CIP). Neste período, as indústrias farmacêuticas, para contornar o controle dos preços feito pela CIP tomaram algumas medidas; tais como, o uso de matéria prima de qualidade duvidosa, superfaturamento, alteração (de concentração, apresentação, formulação etc.) dos produtos para justificar o aumento dos preços ${ }^{(45)}$.

O CIP foi extinto em 1990, com isto, o preço dos medicamentos foram liberados, a partir de agosto daquele ano. No entanto, a liberação de preços não aconteceu de forma total, os medicamentos de uso contínuo permaneceram com preços controlados. Somente a partir de maio de 1992 os preços dos medicamentos foram liberados ${ }^{(45)}$. 
Estabeleceu-se o Preço Máximo ao Consumidor; ou seja, o preço que deveria ser cobrado pelo comércio varejista de medicamentos. Este preço cobrado incluía os gastos dos compradores e os lucros das farmácias e drogarias. Além disto, a lista apresentava uma seção denominada Preço de Fábrica, que eram os preços máximos que os distribuidores de medicamentos e laboratórios deveriam cobrar para comercializar no mercado brasileiro, preço este que era cobrado às farmácias e drogarias. Com os preços de medicamentos liberados, estabeleceu-se a margem máxima de lucros para as farmácias, verificando-se uma elevação de $43,99 \%$ do preço médio de medicamentos e uma queda de $22,53 \%$ nas quantidades vendidas ${ }^{(46)}$.

Importante registrar que na década de 1990, a maioria das economias da América Latina passou por um processo de "desregulação" da qual não escapou o mercado de medicamentos. Esperava-se que, sem a intervenção do Estado, a competição entre empresas seria estimulada e, como consequência, os preços dos produtos sofreriam uma redução. Entretanto, não foi o que ocorreu ${ }^{37}$. Em adição, a ratificação do acordo sobre os Aspectos dos Direitos de Propriedade Intelectual Relacionados com o Comércio (TRIPS) em 1996, incluindo uma provisão para a concessão de patentes a inventos em pipeline, remodelaram a indústria farmacêutica local ${ }^{(47)}$.

Os preços aumentaram e o consumo diminuiu. Em contrapartida, os países desenvolvidos que não realizaram uma "desregulação" tão forte no mercado de medicamentos obtiveram melhores resultados em termos de acesso. Entre as medidas regulatórias adotadas por estes países, ressalta-se a política de medicamentos genéricos que resultou em uma das mais poderosas ferramentas para ampliação do acesso aos medicamentos ${ }^{(48)}$.

Alguns estudos realizados por Bermudez et al $(2000)^{(47)}$ no período de abril de 1992 e abril de 1993 demonstraram que frente a uma inflação estimada em 1.608\%, os preços de alguns medicamentos aumentaram em $2.600 \%$ na tentativa de recuperar a margem de lucro perdida durante o período com controle governamental. Isto dificultou ainda mais o acesso da população aos medicamentos. Em 1993 os preços voltaram a ser controlados.

No ano seguinte, 1994, até 1996, a política teve 45,7\% de aumento dos preços medido pela Índice de Preços ao Consumidor da Fundação Instituto de Pesquisa Econômica (IPCFIPE), contra inflação geral de 60,3\%; além do fato de, no ano de 1995 ter ocorrido redução de 3,7\% no preço médio. No final de 1996, novamente ocorre à liberdade de preços para o setor. Em 1997, a Secretaria de Acompanhamento Econômico do Ministério da Fazenda (SEAE-MF), que anteriormente acompanhava de perto os acordos estabelecidos entre o governo e a indústria farmacêutica, se afastou, dando liberdade às indústrias, que fixaram seus preços conforme julgavam ser necessário. Novamente, foi necessária intervenção do Governo, uma vez que os 
reajustes que ocorreram foram bastante elevados. Em 1998, foi determinado que as indústrias devessem comunicar à SEAE o aumento dos preços, bem como justificá-los ${ }^{(47)}$.

Em novembro de 1999, por conta de diversas denúncias - por suspeita de práticas lesivas ao consumidor, relacionadas à política de preços dos medicamentos - contra as indústrias farmacêuticas que atuavam na época, foi criada uma Comissão Parlamentar de Inquérito dos Medicamentos (CPI-Medicamentos) no Congresso Nacional ${ }^{45}$. O mercado farmacêutico nacional estava marcado por diversos casos de falsificação de medicamentos, comprometendo a segurança e a qualidade dos produtos oferecidos à população( ${ }^{(35)}$.

A CPI-Medicamentos foi instalada na Câmara dos Deputados, em novembro de 1999, com o objetivo de investigar os reajustes exorbitantes de preços e a falsificação de remédios; práticas que, na época, foram alvo de constantes denúncias veiculadas na mídia. A comissão parlamentar de inquérito também investigou acordos firmados entre laboratórios para impor preços de remédios e determinar a divisão do mercado entre eles, o que caracterizava a formação de cartel, impedindo, consequentemente, a livre concorrência do setor ${ }^{(45)}$.

Durante seis meses, a CPI-Medicamentos realizou 64 reuniões, entre audiências públicas e diligências investigativas. Até o final dos trabalhos, em maio de 2000, a CPI-Medicamentos quebrou o sigilo fiscal e bancário de 34 laboratórios e cinco distribuidoras, o que resultou em cerca de 150 mil documentos que também serviram de subsídios para as ações da comissão. $\mathrm{O}$ relatório final trouxe cem sugestões e recomendações a vários órgãos do governo para aperfeiçoar os mecanismos de produção e comercialização de medicamentos no país ${ }^{(45)}$.

Como resultado das investigações; por exemplo, a CPI-Medicamentos sugeriu e a Secretaria do Direito Econômico do Ministério da Justiça indiciasse 42 laboratórios farmacêuticos, seja por prejudicar a livre concorrência, aumentar arbitrariamente os lucros ou impor preços excessivos. Estudos apresentados na CPI-Medicamentos mostraram que entre 1990 e 1998, houve um aumento de 300 por cento nos preços dos medicamentos. Nesse período, apesar da produção de medicamentos ter se mantido estável - em torno de um bilhão e 600 milhões de unidades - o faturamento do setor passou de três bilhões e quatrocentos milhões de dólares para dez bilhões e trezentos milhões de dólares ${ }^{(45)}$.

A CPI-Medicamentos prestou um grande serviço à sociedade brasileira, dando o primeiro passo para a legalização e comercialização dos genéricos. No relatório final, consta que foi opinião unânime, nos debates e depoimentos, que os medicamentos genéricos representam um instrumento para a regulação dos preços do mercado e para a melhoria do acesso da população aos remédios que necessita ${ }^{(45)}$. 
Neste contexto, a Lei $\mathrm{n}^{\mathrm{o}}$ 9.782, de 26 de janeiro de 1999, define o Sistema Nacional de Vigilância Sanitária e cria a Agência Nacional de Vigilância Sanitária (ANVISA), com o objetivo de proteger e garantir que os produtos oferecidos no mercado tivessem qualidade e fossem seguros $^{(9)}$. A Portaria MS/GM n 354 , de 11 de agosto de 2006, aprova e promulga o Regimento Interno da Agência Nacional de Vigilância Sanitária (ANVISA), dando outras providências $^{(49)}$.

Já a Lei $n^{\circ} 9.787$, de 10 de fevereiro de $1999,{ }^{(10)}$ altera a Lei ${ }^{\circ} 6.360$, de 23 de setembro de 1976, estabelece o medicamento genérico, dispõe sobre a utilização de nomes genéricos em produtos farmacêuticos e vigilância sanitária, entre outras providências. A RDC/ANVISA no 391, de 9 de agosto de 1999, aprova o regulamento técnico para medicamentos genéricos ${ }^{(50)}$.

Ambos os fatos - a promulgação da lei e a criação da Anvisa - representaram uma mudança significativa na política governamental sobre este segmento e causaram grande impacto na estrutura do mercado farmacêutico brasileiro. Com a implementação da política de genéricos, o mercado, que até então era dominado por empresas multinacionais, começou a oferecer espaço para o crescimento das indústrias nacionais. Estas indústrias passaram a investir pesadamente no setor e alavancaram um crescimento significativo do mercado ${ }^{(36)}$. A validade de uma patente farmacêutica no Brasil é de 20 anos e após este período é possível lançar medicamentos genéricos no mercado.

O conceito de genérico implica um medicamento similar a um produto de referência ou inovador, que se pretende ser intercambiável, geralmente produzido após a expiração ou renúncia da proteção patentária ou de outros direitos de exclusividade, comprovada a sua eficácia, segurança e qualidade, e designado pela Denominação Comum Brasileira $-\operatorname{DCB}^{(9,10)}$. Portanto, primeiramente, deve-se demonstrar a eficácia e a qualidade do medicamento genérico, e para isso é necessário contar com um bom sistema de farmacovigilância e um rigoroso esquema de registro ${ }^{(36)}$.

De acordo com a RDC/ANVISA n ${ }^{\circ} 16$, de 2 de março de $2007^{(51)}$, estas condições devem ser cumpridas para que não haja problemas de credibilidade dos medicamentos e sim promoção do acesso e dos benefícios sociais. Para obtenção de registros de medicamentos genéricos no Brasil e, por conseguinte, do direito à comercialização de medicamentos desta categoria, é necessária a apresentação, à Anvisa, de um dossiê completo descrevendo as etapas: (1) de produção; (2) controle de qualidade; (3) validação dos métodos utilizados; (4) estudos comprobatórios de estabilidade; (5) equivalência farmacêutica e bioequivalência; (6) diretrizes de rotulagem e bula; (7) embalagem primária; (8) embalagem secundária. Alguns outros 
documentos são indispensáveis, como a autorização de funcionamento e o Certificado de Boas Práticas de Fabricação (CBPF), concedidos pela Anvisa ${ }^{(51)}$.

Dois medicamentos são considerados equivalentes terapêuticos quando apresentam a mesma eficácia clínica e o mesmo potencial para gerar efeitos $\operatorname{adversos}^{(51)}$. A biodisponibilidade relativa e a equivalência farmacêutica são elementos utilizados no Brasil para comprovar a equivalência terapêutica do medicamento genérico a um medicamento para o qual já houve comprovação de eficácia clínica, o denominado medicamento de referência ${ }^{(36)}$.

Ao longo dos últimos anos, um novo e desafiante cenário no registro de medicamentos genéricos vem sendo gradativamente incorporado na rotina de análise dos dossiês de registro apresentados à Agência Nacional de Vigilância Sanitária (Anvisa) pela indústria farmacêutica. Há estudos que apontam a necessidade de mudanças racionais nos procedimentos de registro de medicamentos genéricos no Brasil, com foco nas auditorias de registro e na qualidade dos dossiês de registro apresentados pela indústria farmacêutica ${ }^{(36)}$.

Os conceitos incorporados na regulação dos medicamentos genéricos; tais como, genéricos inéditos, medicamentos priorizados e medicamentos clones, são fatores relacionados ao ganho ou perda de eficiência quanto aos prazos para obtenção de registro de medicamentos genéricos no Brasil; variando em 2010, de até 626 dias para medicamentos não priorizados e 429 dias para medicamentos com análise priorizada - que, porém, diminuíram para 323 dias com os procedimentos de análise in loco (auditorias de registro), e aumentaram para 1.018 dias com arquivamentos temporários solicitados pelas indústrias farmacêuticas ${ }^{(36)}$.

Fiuza e Caballero $(2010)^{(37)}$, registram que mudanças na legislação brasileira durante os anos 1990 e a Lei dos Genéricos em 1999, contribuíram para a substituição de medicamentos de referência por genéricos no mercado nacional. Em adição, os autores inferem que a entrada de versões genéricas de medicamentos pioneiros já sem patente nas várias classes terapêuticas, contribuíram para a retomada de controles de preços na virada do século. Por fim, o tamanho do mercado potencial, a concentração de mercado e a expiração da patente de medicamentos de referências contribuíram para o êxito da Política de Medicamentos Genéricos no Brasil.

Desde que chegaram ao mercado, os medicamentos genéricos ampliaram substancialmente o acesso a tratamentos para milhares de consumidores, contribuindo para estabelecer novos padrões de qualidade para os medicamentos no mercado local e mudaram a face da indústria farmacêutica instalada no país. Em adição, os medicamentos similares, desde 2015, estão submetidos às exigências de bioequivalência e outros testes, tornando-se, em termos práticos, "genéricos de marca"(31). As Resoluções RDC/ANVISA n ${ }^{\circ} 133 / 2003,{ }^{(52)} \mathrm{n}^{\circ}$ 
$134 / 2003,{ }^{(53)} \mathrm{n}^{\mathrm{o}} 135 / 2003^{(54)}$ e $\mathrm{n}^{\mathrm{o}} 16 / 2007^{(51)}$ regulamentam os requisitos necessários para o registro do medicamento similar, proporcionando, assim, uma evolução da legislação relacionado a esta classe de medicamentos, uma vez que determina a apresentação das mesmas provas necessárias para registro de medicamento genérico.

No Brasil existem hoje 120 fabricantes de genéricos, responsáveis por mais de 3,8 mil registros de medicamentos que derivam mais de 21,7 mil apresentações comerciais. $\mathrm{O}$ faturamento do setor que se aproximou dos 8,6 bilhões de reais em 2018, deve avançar acima dos $10 \%$ neste ano, puxando o crescimento das vendas de todo o restante da indústria farmacêutica brasileira, que crescerá aproximadamente $12 \%$ em valores ${ }^{(55)}$. Entre as 10 maiores farmacêuticas instaladas no país, 9 possuem linha de fabricação de medicamentos genéricos, ou seja, muitas empresas que desenvolveram e respondem pela comercialização de produtos de marca conhecidas internacionalmente, atualmente também se dedicam à fabricação de genéricos. Do ponto de vista econômico, os genéricos também proporcionaram avanços sem precedentes para a indústria farmacêutica no Brasil. O rigor regulatório que garante a qualidade desses medicamentos demandaram investimentos superiores a 1,5 bilhão de reais nos últimos 10 anos em ampliação e construção de unidades fabris ${ }^{(55)}$.

Desde o ano 2000 até 2019, 5.723 medicamentos genéricos foram registrados. Destes, 2.398 registros foram cancelados, restando 3.325 medicamentos genéricos com registros válidos. Ressalta-se, entretanto, que alguns medicamentos genéricos possuem mais de uma forma farmacêutica vinculadas ao mesmo processo de registro. Assim, sendo, para os dados até 05 de agosto de 2019, nas listas de medicamentos genéricos com registros válidos em que há a especificação da forma farmacêutica, são consideradas 3.729 formas farmacêuticas. Dentre as 3.729 formas farmacêuticas de medicamentos genéricos com registros válidos, há 644 diferentes princípios ativos isolados ou em associação. 133 empresas são detentoras dos registros das 3.729 formas farmacêuticas de medicamentos genéricos com registros válidos. Até 2019 foram registrados 1.039 medicamentos genéricos inéditos. Deste total, 708 para determinada substância ativa ou associação, 214 para forma farmacêutica e 104 para concentração. Esses dados refletem o total de registros de medicamentos genéricos inéditos, tanto os válidos como os atualmente cancelados ${ }^{(56)}$.

Em 2017 foram comercializadas 1,2 bilhão de unidades de genéricos contra 1,1 bilhão no ano anterior, o que resultou numa expansão de 11,78\%. Em valores, foram registrados R 7,5 bilhões em vendas no ano passado, já considerados os descontos concedidos ao varejo. No primeiro semestre de 2018, as vendas de genéricos registraram crescimento de $10 \%$ em 
unidades. Nesse período, foram comercializadas 676,4 milhões de unidades no varejo farmacêutico contra 614,2 milhões no primeiro semestre de 2017. No mesmo intervalo o mercado farmacêutico total cresceu 6\%. Em junho de 2019, o faturamento com as vendas de genéricos já representa $21 \%$ das farmácias. No mesmo período em 2018 a representatividade dos genéricos era de 19\%. Vale lembrar que, por Lei, os genéricos custam 35\% menos que os medicamentos de referência. No entanto, diante da concorrência acirrada, na prática, os descontos oferecidos pelos fabricantes podem chegar em até 60\% no varejo (FEBRAFAR, 2019). Os genéricos já proporcionaram uma economia de mais de $\mathrm{R} \$ 150$ bilhões em gastos com medicamentos nestes 21 anos de história no país ${ }^{(55)}$.

Tão importante quanto a atribuir novo protagonismo ao capital brasileiro nesse setor produtivo da economia nacional, foi o papel de promover seu crescimento, tanto no que compete à gama de produtos ofertados, como ao que diz respeito à ramificação produtiva territorial/regional. A difusão territorial e regional promovida pela expansão produtiva dos medicamentos genéricos no Brasil pode ser considerada relevante, pois se ampliou territorialmente dos, inicialmente, três estados (GO, RJ e SP), em 2000, para doze Estados (AL, BA, CE, ES, GO, MG, MS, PE, PR, RJ, SC e SP), em 2017, perfazendo um crescimento de $39,2 \%$ no quantitativo de plantas industriais produtoras de medicamentos genéricos no Brasil, sendo que $41 \%$ de indústrias são de capital nacional e 34,9\% dessas indústrias pertencem ao capital estrangeiro ${ }^{(26)}$.

Atualmente, os 10 maiores laboratórios de genéricos do Brasil em volume são: (1) EMS Pharma; (2) Neo Química; (3) Teuto Brasileiro; (4) Medley; (5) Eurofarma; (6) Germed Pharma; (7) Cimed; (8) Aché; (9) Sandoz do Brasil; (10) Prati-Donaduzzi ${ }^{(57)}$. Os 10 maiores laboratórios de genéricos do Brasil em valor (R\$) são: (1) SEM Pharma; (2) Medley; (3) Eurofarma; (4) Neo Química; (5) Sandoz do Brasil; (6) Germed Pharma; (7) Aché; (8) Teuto Brasileiro; (9) Legrand; (10) Nova Química ${ }^{(58)}$.

Ao se perseverar a concentração produtiva na região Sudeste $(77,6 \%)$, viabilizou-se um movimento de desconcentração relativa da indústria. Dessa forma, corrobora-se a hipótese inicial deste trabalho de que a política pública de saúde de criação dos medicamentos genéricos no Brasil atuou positivamente no setor industrial farmacêutico brasileiro, tornando-se, também, uma política pública industrial, gerando crescimento econômico setorial e favorecendo certo grau de ampliação produtivo territorial/regional, ultrapassando as fronteiras da região Sudeste ${ }^{(26)}$. 
Com $34,07 \%$ de participação de mercado e respondendo por $85 \%$ dos produtos dispensados pelo Programa Farmácia Popular, os genéricos se constituíram no principal instrumento de saúde pública focado no acesso a medicamentos no Brasil. $70 \%$ dos brasileiros compram ou já compraram medicamentos genéricos. 33\% dos medicamentos prescritos no Brasil são genéricos. $34 \%$ dos medicamentos vendidos no Brasil são genéricos. 16 empresas associadas responsáveis por mais de $82 \%$ do mercado Brasileiro de genéricos. 35\% dos genéricos são 35\% mais baratos que os medicamentos de referência. $60 \%$ dos genéricos são, em média, $60 \%$ mais baratos que os medicamentos de referência nas farmácias ${ }^{(55)}$.

A prescrição de medicamentos genéricos no país aumentou 65\% de 2015 a 2018. Mais barata, essa versão de medicamentos foi prescrita em 34\% das 115 milhões de receitas médicas emitidas entre fevereiro de 2017 e fevereiro de 2018 ${ }^{(59)}$. Os medicamentos genéricos representam um ramo impulsionador da economia, além de ampliar o acesso da população à saúde, provocando relevante impacto social. Importante destacar que a Lei $n^{\circ} 12.349$, de 15 de dezembro de 2010, que regula as compras governamentais, incentiva a preferência de produtos nacionais nos processos de licitação, e uma preferência adicional se esses produtos forem resultado de desenvolvimento e inovação tecnológica realizado no país ${ }^{(60)}$.

Quanto aos brasileiros que utilizam medicamentos genéricos, Mishuk et al., (2018) ${ }^{(25)}$, demonstram que idosos (idade), pessoas com baixo nível socioeconômico (renda) e minorias (raças) possuem percepções negativas acerca desta classe de medicamentos. Nardi $(2015)^{(61)}$ registra que a visão negativa em relação aos genéricos, observada em pessoas de menor renda e mais idosas, levanta preocupação, pois esses grupos da população têm maior necessidade de medicamentos que tenham custos reduzidos, devido à restrição orçamentária ou à concomitância de doenças crônicas e, consequentemente, à utilização de maior número de medicamentos. Mishuk et al. (2018) ${ }^{(25)}$ não encontraram diferenças na utilização por homens ou mulheres.

Médicos, comércio farmacêutico e indústria farmacêutica se mostraram resistentes aos genéricos. A indústria farmacêutica, numa tentativa de reprimir a venda de genéricos, veiculou propaganda que a intercambialidade feita nas farmácias era irregular; fornecendo receituários médicos padronizados aos profissionais prescritores com frases que proibiam a intercambialidade. Para coibir esse comportamento, a Agência Nacional de Vigilância Sanitária (ANVISA) interveio com a publicação da RDC/ANVISA n ${ }^{\circ}$ 135, de 29 de maio de 2003, que aprova o regulamento técnico para medicamentos genéricos, proibindo os médicos de não autorizar a troca do medicamento de marca por um genérico ${ }^{(54)}$. Em tempo, a ANVISA investiu 
substancialmente em estratégias educativas para informar e esclarecer a sociedade brasileira quanto aos benefícios dos medicamentos genéricos. A mídia também se mostrou um veículo de comunicação eficiente para a implantação dos genéricos no Brasil ${ }^{(62)}$.

De acordo com Caliari e Ruiz (2013), ${ }^{(33)}$ a política de medicamentos genéricos transformou a estrutura produtiva brasileira no campo farmacêutico. A competitividade entre as empresas impulsionou também as pesquisas e inovações tecnológicas. Ressaltam a importância do Banco Nacional de Desenvolvimento Econômico e Social (BNDES) para o apoio às indústrias farmacêuticas nacionais. Houve o fortalecimento do Complexo Econômico Industrial da Saúde no país ${ }^{(62)}$.

A política dos medicamentos genéricos também se apresenta com uma perspectiva futura para a indústria farmacêutica brasileira com a viabilidade da produção de medicamentos biossimilares18, que podem ser entendidos como genéricos tecnologicamente sofisticados dos medicamentos biológicos. Assim, as empresas farmacêuticas nacionais, que desenvolvam pesquisas e novas competências tecnológicas, tendo como gênesis os medicamentos genéricos, também poderão prover desenvolvimentos nessa nova área de medicamentos ${ }^{(26)}$.

Cabe salientar que, apesar de não ter sido foco deste trabalho, a implementação da política pública de genéricos, além de prover transbordamentos econômicos e produtivos ao setor industrial farmacêutico, pôde influenciar positivamente outras questões tais como: um aumento do PIB industrial, geração de emprego e renda, redução dos gastos da família brasileira com medicamentos, realização de investimentos em aumento de capacidade produtiva da indústria farmacêutica e aumento da competitividade industrial brasileira, sendo esses interessantes tópicos para estudos futuros ${ }^{(26)}$.

Por fim, Luiza et al. (2017), ${ }^{(28)}$ em uma análise da Assistência Farmacêutica no Brasil, destacam a importância da política de medicamentos genéricos; em especial, quanto aos desafios e dificuldades do sistema de saúde brasileiro, principalmente no que diz respeito ao acesso universal, diversidade geográfica, variação epidemiológica, mudança de padrões de morbidade e mortalidade associadas a doenças transmissíveis e não-transmissíveis e as desigualdades sociais.

\section{CONCLUSÕES}

A criação da Anvisa e a estratégia de Medicamentos Genéricos representaram uma mudança significativa na política governamental sobre o segmento farmacêutico, proporcionando impacto na estrutura do mercado farmacêutico brasileiro. O mercado, que até 
então, era dominado por empresas multinacionais, começou a oferecer espaço para o crescimento das indústrias nacionais. Estas indústrias passaram a investir no setor e alavancaram um crescimento significativo. A implantação e implementação da Política de Medicamentos Genéricos no Brasil está em conformidade com a dos nos países de média e alta renda; respeitando-se as diferenças regionais e as opções regulatórias.

A produção de medicamentos genéricos cresceu, fortalecendo a indústria farmacêutica de capital nacional. Desconcentrou e ampliou territorialmente dos, inicialmente, três Estados (GO, RJ e SP), em 2000, para doze estados (AL, BA, CE, ES, GO, MG, MS, PE, PR, RJ, SC e SP), em 2017. Infere-se uma relação entre os medicamentos genéricos e o Complexo Industrial da Saúde; ou seja, um compromisso político que liga as necessidades do sistema de saúde às políticas industriais e estratégia de estímulo à concorrência. Contudo, registrou-se um pequeno aumento nos gastos e inovação em P\&D e inovação nessas empresas, proporcionando uma baixa competitividade das empresas domésticas decorrente de suas fracas capacidades tecnológicas, resultado de uma política industrial de demanda puxada sem o apoio de uma política industrial tecnológica.

As intervenções utilizadas pelo Governo Federal para a implementação dos medicamentos genéricos foram as educativas direcionadas aos usuários, farmacêuticos e prescritores, de incentivo financeiro, administrativo/gerencial, uso de tecnologias da informática para prescrição/dispensação eletrônica.

Usuários com menor renda são os mais propensos a usar medicamentos genéricos, sendo as evidências heterogêneas em relação à associação entre uso de medicamentos genéricos e sexo, idade ou raça/etnia. Usuários com maior grau instrucional e com renda mais alta, não respondem significativamente a estratégia do uso de medicamentos genéricos.

Em síntese, a Política de Medicamentos Genéricos se mostrou acertada, permitindo ganhos estáticos de aumento da oferta e redução de preços; mas, ainda precisa avançar quanto a pesquisa, desenvolvimento e inovação no contexto do complexo industrial da saúde e dos determinantes sociais e de equidade.

\section{REFERÊNCIAS BIBLIOGRÁFICAS}

1. Dallari-Bucci MP. O conceito de política pública em direito. In: Dallari-Bucci MP. (Org.). Políticas públicas: Reflexões sobre o conceito jurídico. 2006. São Paulo: Saraiva. ISBN 9788502060548 
2. Abbagnano N. Dicionário de filosofia. 1998. $2^{\text {a }}$ ed. São Paulo: Martins. Fontes. ISBN 85336-0865-9

3. BRASIL. Casa Civil da Presidência da República. Instituto de Pesquisa Econômica Aplicada. Avaliação de políticas públicas: guia prático de análise ex ante. 2018. Brasília: Ipea. ISBN: 978-85-7811-319-3

4. Serafim MP, Dias RB. Análise de política: Uma revisão da literatura. Cadernos Gestão Social. 2012;3(1):121-34. ISSN: 1982-5447

5. Lessa G, Kuehlkamp, Valdete M, Erdmann AL, Andrade SR. Análise de Políticas Públicas de Saúde: Revisão Narrativa. Cogitare Enfermagem. 2015;20(1):191-197. DOI: http://dx.doi.org/10.5380/ce.v20i1.36

6. Lopes FAD. Análise da equidade da política nacional de medicamentos no período de 1998 a 2013. 2016. Belo Horizonte, Dissertação (Mestrado). Escola de Governo Professor Paulo Neves de Carvalho (Programa de Mestrado em Administração Pública). Fundação João Pinheiro. Minas Gerais.

7. BRASIL. Ministério da Saúde. Portaria GM/MS nº 3.916, de 30 de outubro de 1998. Aprova a Política Nacional de Medicamentos. DOU de 10 de novembro de 1998s.1, n.215-E, p.18. Brasília. Distrito Federal.

8. BRASIL. Conselho Nacional de Saúde. Resolução CNS n 338, de 06 de maio de 2004. Aprova a Política Nacional de Assistência Farmacêutica. Brasília. Distrito Federal.

9. BRASIL. Congresso Nacional. Lei $\mathrm{n}^{\circ}$ 9.782, de 26 de janeiro de 1999. Define o Sistema Nacional de Vigilância Sanitária, cria a Agência Nacional de Vigilância Sanitária, dando outras providências. Publicada no DOU de 27 de janeiro de 1999. Brasília. Distrito Federal.

10. BRASIL. Congresso Nacional. Lei $n^{\circ}$ 9.787, de 10 de fevereiro de 1999. Altera a Lei no 6.360, de 23 de setembro de 1976, que dispõe sobre a vigilância sanitária, estabelece o medicamento genérico, dispõe sobre a utilização de nomes genéricos em produtos farmacêuticos e dá outras providências. Publicado no DOU de 11 de fevereiro de 1999. Brasília. Distrito Federal.

11. BRASIL. Ministério da Saúde. Secretaria de Ciência, Tecnologia e Insumos Estratégicos. Departamento de Ciência e Tecnologia. Diretrizes metodológicas: elaboração de revisão sistemática e metanálise de ensaios clínicos randomizados. Brasília: Editora do Ministério da Saúde, 2012. 92 p.: il. - (Série A: Normas e Manuais Técnicos). ISBN 978-85-334-1951-3 
12. Lavis, JN, Oxman AD, Lewin S, Fretheim A. SUPPORT Tools for evidence-informed health Policymaking (STP). Introduction. Health Research Policy and Systems. 2009;7(1):I1 doi:10.1186/1478-4505-7-S1-I1.

13. Ercole FF, Melo LS, Alcoforado CLGC. Revisão integrativa versus revisão sistemática. Revista Mineira de Enfermagem. 2014;18(1):9-12. DOI: http://www.dx.doi.org/10.5935/14152762.20140001

14. Mendeley JA, Thomson M, Coyne RP. How and When to Reference. 2017. https://www.mendeley.com/guides/web

15. Ouzzani M, Hammady H, Fedorowicz Z, Elmagarmid A. Rayyan: A web and mobile app for systematic reviews. Systematic Reviews. 2016;5:210. DOI: 10.1186/s13643-016-0384-4. https://rayyan.qcri.org/users/sign_in

16. Moher D, Liberati A, Tetzlaff J, Altman DG. The PRISMA Group. Preferred Reporting Items for Systematic Reviews and Meta-Analyses: The PRISMA Statement. PLoS Med. 2009;6(7):e1000097. doi:10.1371/journal.pmed1000097. www.prisma-statement.org

17. Hamilton ON. National Collaborating Centre for Methods and Tools. PROGRESS framework: Applying an equity lens to interventions. 2015. McMaster University. https://www.nccmt.ca/knowledge-repositories/search/234

18. Shea BJ, Grimshaw JM, Wells GA, Boers M, Andersson N, Hamel C, Porter AC, Tugwell P, Moher D, Bouter LM. Development of AMSTAR: a measurement tool to assess the methodological quality of systematic reviews. BMC Medical Research Methodology. 2007;7(10). https://doi.org/10.1186/1471-2288-7-10.

19. Mendes KDS, Silveira RCCP, Galvão CM. Revisão integrativa: método de pesquisa para a incorporação de evidências na saúde e na enfermagem. Texto Contexto Enferm. 2008;17(4):758-64. ISSN 1980-265X

20. Bastos JLD, Duquia RP. Um dos delineamentos mais empregados em epidemiologia: estudo transversal. Scientia Medica. 2007; 17(4):229-232. ISSN 1980-6108

21. Oliveira MA, Vellarde GC, Sá RAM. Entendendo a pesquisa clínica III: estudos de coorte. Femina. 2015;43(3):105-110. ISSN 0100-7254

22. Silva EN, Galvão TF, Pereira MG, Silva MT. Estudos de avaliação econômica de tecnologias em saúde: roteiro para análise crítica. Rev Panam Salud Publica. 2014;35(3):21927. ISSN: $1020-4989$ 
23. BRASIL. Conselho Nacional de Saúde (CNS). Resolução n ${ }^{\circ} 466$ de 12 de dezembro de 2012. Aprova as diretrizes e normas regulamentadoras de pesquisas envolvendo seres humanos. Brasília. Distrito Federal.

24. BRASIL. Conselho Nacional de Saúde (CNS). Resolução no 510, de 07 de abril de 2016. Dispõe sobre as normas aplicáveis a pesquisas em Ciências Humanas e Sociais cujos procedimentos metodológicos envolvam a utilização de dados diretamente obtidos com os participantes ou de informações identificáveis ou que possam acarretar riscos maiores o que os existentes na vida cotidiana. Brasília. Distrito Federal.

25. Mishuk AU, Qian J, Howard JN, Harris I, Frank G, Kiptanui Z, Hansen R. The Association Between Patient Sociodemographic Characteristics and Generic Drug Use: A Systematic Review and Meta-analysis. J Manag Care Spec Pharm. 2018;24(3):252-264. doi: 10.18553/jmcp.2018.24.3.252.

26. Manhães E, Hasenclever L. A territorialidade da política pública dos medicamentos genéricos no Brasil: 2000/2017. Revista de Políticas Públicas. 2018;22(2):987-1008. DOI: http://dx.doi.org/10.18764/2178-2865.v22n2 p987-1008

27. Guttier MC, Silveira MPT, Luiza VL, Bertoldi AD. Impacto de intervenções para promoção do uso de medicamentos genéricos: revisão sistemática. Ciênc. saúde coletiva . 2017;22(8):2627-2644. https://doi.org/10.1590/1413-81232017228.05762017.

28. Luiza VL, Oliveira MA, Chaves GC, Flynn MB, Bermudez JAZ. Pharmaceutical Policy in Brazil. In: Babar ZUD. (eds) Pharmaceutical Policy in Countries with Developing Healthcare Systems. Adis, Cham. ISBN978-3-319-51673-8. https://doi.org/10.1007/978-3319-51673-8_7

29. Fonseca EM, Shadlen KC. Promoting and regulating generic medicines: Brazil in comparative perspective. Rev Panam Salud Publica. 2017;41:e5. doi: 10.26633/RPSP.2017.5 30. Barbosa K, Silva E. The Pattern of Entry of Generic Drugs into the Brazilian Pharmaceutical Market. Revista Brasileira de Econometria. 2017;37(1):1-18. https://pdfs.semanticscholar.org/8769/f618e63cd54206c2864e26c32acc0ecd9a8d.pdf

31. Vasconcelos DMM, Chaves GC, Azeredo TB, Silva RM. Política Nacional de Medicamentos em retrospectiva: um balanço de (quase) 20 anos de implementação. Ciênc. saúde coletiva. 2017;22(8):2609-2614. https://doi.org/10.1590/1413-81232017228.02432017. 32. Lira CA, Oliveira JN, Andrade MS, Vancini-Campanharo CR, Vancini RL. Knowledge, perceptions and use of generic drugs: a cross sectional study. Einstein. 2014;12(3):267-273. DOI: $10.1590 / \mathrm{S} 1679-45082014 \mathrm{AO} 3125$ 
33. Caliari T, Ruiz RM. Brazilian pharmaceutical industry and generic drugs policy: Impacts on structure and innovation and recent developments. Science and Public Policy. 2014;41(2):245-256. http://hdl.handle.net/10.1093/scipol/sct053

34. Kaplan WA, Ritz LS, Vitello M, Wirtz VJ. Policies to promote use of generic medicines in low and middle income countries: A review of published literature, 2000-2010. Health Policy. 2012;106(3):211-24. doi: 10.1016/j.healthpol.2012.04.015.

35. Araújo LU, Albuquerque KT, Kato KC, Silveira GS, Maciel NR, Spósito PA, et al. Medicamentos genéricos no Brasil: panorama histórico e legislação. Rev Panam Salud Publica. 2010;28(6):480-92. ISSN: 1020-4989

36. Soares MLC, Garcia LP, Oliveira SRM, Rocha DB, Piras SS, Braga HA. Eficiência regulatória: Análise de sobrevivência aplicada a trajetória de registro de medicamentos genéricos. Texto para discussão $n^{\circ}$ 1772. Instituto de Pesquisa Econômica Aplicada. Brasília: Rio de Janeiro: Ipea. 2012. ISSN 1415-4765

37. Fiuza EPS, Caballero B. Estimações de entrada de medicamentos genéricos no brasil usando modelos de contagem modelos ordenados versus. Instituto de Pesquisa Econômica Aplicada (IPEA). Texto para discussão $\mathrm{n}^{\circ}$ 1511. Rio de Janeiro. 2010. ISSN 1415-4765

38. Quental C, Abreu JC, Bomtempo JV, Gadelha CAG. Medicamentos genéricos no Brasil: impactos das políticas públicas sobre a indústria nacional. Ciênc. saúde coletiva . 2008;13(Suppl):619-628.http://dx.doi.org/10.1590/S1413-81232008000700011

39. Dias CRC, Romano-Lieber NS. Processo da implantação da política de medicamentos genéricos no Brasil. Cad. Cad. Saúde Pública. 2006;22(8):1661-1669. ISSN 0102311X. https://doi.org/10.1590/S0102-311X2006000800014.

40. Bertoldi AD, Barros AJD, Hallal PC. Generic drugs in Brazil - Known by many, used by few. Cad. Saúde Pública. 2005;21(6):1808-1815. https://doi.org/10.1590/S0102$\underline{311 \times 2005000600029}$

41. Bermudez JAZ. Medicamentos genéricos: uma alternativa para o mercado brasileiro. Cad. Saúde Públ. 1994;10(3):368-378.https://doi.org/10.1590/S0102-311X1994000300016.

42. Silva KP, Rodrigues SL. Análise e avaliação da política nacional de medicamentos genéricos no Brasil. Belém. Trabalho de Conclusão de Curso (Graduação) - Universidade Federal do Pará: Faculdade de Farmácia. Pará. 2019.

43. Godoy MR, Oliveira ALR, Câmara MRG. O controle de preços na indústria farmacêutica do Brasil. Porto Alegre. Tese (Doutorado) - Universidade Federal do Rio Grande do Sul: 
Programa de Pós-Graduação em Economia. Rio Grande do Sul. 2004. http://www.academia.edu/3178611

44. Brasil. Congresso Nacional. Lei ${ }^{\circ}$ 6.360, de 23 de setembro de 1976. Dispões sobre a vigilância sanitária a que ficam sujeitos os medicamentos, as drogas, os insumos farmacêuticos e correlatos, cosméticos, saneantes e outros produtos, entre outras providências. Publicado no DOU de 24 de setembro de 1976. Brasília. Distrito Federal.

45. Brasil. Câmara dos Deputados Federais. Relatório da Comissão Parlamentar de Inquérito: Medicamentos. Deputado Ney Lopes (Relator). Brasília, 30 de maio de 2000. Brasília. Distrito Federal. https://www2.camara.leg.br/atividade-legislativa/comissoes/comissoestemporarias/parlamentar-de-inquerito/51-legislatura/cpimedic/cpimedic_relp.PDF

46. Dias CC. Medicamentos genéricos no Brasil de 1999 a 2002: Análise da legislação, aspectos conjunturais e políticos. São Paulo. Mestrado (Dissertação) - Universidade de São Paulo (Faculdade de Saúde Pública). São Paulo. 2003. DOI 10.11606/D.6.2003.tde-26112003223713

47. Bermudez JAZ, Epsztejn R, Oliveira MA, Hasenclever L. O acordo TRIPS da OMC e a proteção patentária no Brasil: mudanças recentes e implicações para a produção local e o acesso da população a medicamentos. 2000. Rio de Janeiro; ENSP. 131 p. ISBN-13: 978-8587303028 48. Tobar, F. Economía de los medicamentos genéricos en América Latina. Revista Panam Salud Publica. 2008;23(1):59-67. https://www.scielosp.org/pdf/rpsp/v23n1/a08v23n1.pdf 49. BRASIL. Ministério da Saúde. Portaria GM nº 354, de 11 de agosto de 2006. Aprova e promulga o Regimento Interno da Agência Nacional de Vigilância Sanitária (ANVISA) e da outras providências. Publicada no DOU de 29 de agosto de 2006. Brasília. Distrito Federal. 50. BRASIL. Agência Nacional de Vigilância Sanitária (ANVISA). RDC/ANVISA n ${ }^{\circ} 391$, de 9 de agosto de 1999. Aprova o Regulamento Técnico para Medicamentos Genéricos. DOU, de 10 agosto de 1999. Seção 1, p. 62. Brasília. Distrito Federal.

51. BRASIL. Agência Nacional de Vigilância Sanitária. RDC/ANVISA n ${ }^{\circ}$ 16, de 2 de março de 2007. Aprova o Regulamento Técnico para Medicamentos Genéricos. Publicado no DOU de 16 de fevereiro de 2007. Brasília. Distrito Federal.

52. BRASIL. Ministério da saúde. Agência Nacional de Vigilância Sanitária. RDC/ANVISA $n^{\circ}$ 133, de 29 de maio de 2003. Dispõe sobre o registro de Medicamento Similar e dá outras providências. Diário Oficial da União, Brasília, DF, 2 jun. 2003. Seção 1, p. 25. 
53. BRASIL. Ministério da saúde. Agência Nacional de Vigilância Sanitária. RDC/ANVISA $\mathrm{n}^{\circ}$ 134, de 29 de maio de 2003. Dispõe sobre a adequação dos medicamentos já registrados. Diário Oficial da União, Brasília, DF, 2 jun. 2003. Seção 1, p. 26.

54. BRASIL. Ministério da saúde. Agência Nacional de Vigilância Sanitária. RDC/ANVISA $\mathrm{n}^{\circ}$ 135, de 29 de maio de 2003. Aprova o Regulamento Técnico para Medicamentos Genéricos. Diário Oficial da União, Brasília, DF, 2 jun. 2003.

55. PRÓ-GENÉRICOS (Associação Brasileira das Indústrias de Medicamentos Genéricos). Cláudio Sá. Assessoria de Imprensa Conteúdo Comunicação. 2019. Acesso: 31 de março de 2020. Disponível em: http://progenericos.org.br/dados-do-setor

56. BRASIL. Agência Nacional de Vigilância Sanitária (ANVISA). Gerência Geral de Medicamentos e Produtos Biológicos. Medicamentos genéricos: estatísticas e listas. Atualizado até Diário Oficial da União de 05 de agosto de 2019. Acessado em 01 de abril de 2020. Disponível em: http://portal.anvisa.gov.br/medicamentos-genericos-registrados.

57. IQVIA (Brasil. Ranking em Unidades). Moving Annual Total. (MAT: acumulado dos meses de março de 2017 a fevereiro de 2018). 2018.Canal Varejo. Total Brasil.

58. IQVIA (Brasil. Ranking em Valores). Moving Annual Total. (R\$, a preço PPP). (MAT acumulado dos meses de março de 2017 a fevereiro de 2018). 2018. Canal Varejo. Total Brasil. 59. FEBRAFAR (Federação Brasileira das Redes Associativistas e Independentes de Farmácias). Genéricos ganham impulso com crise e já lideram o crescimento do setor. Imprensa. 15 de junho de 2019. Disponível em: https://www.febrafar.com.br/genericosganham-impulso-com-crise-e-ja-lideram-o-crescimento-do-setor/

60. BRASIL. Congresso Nacional. Lei $\mathrm{n}^{\circ}$ 12.349, de 15 de dezembro de 2010. Regula e incentiva as compras governamentais, dando preferência para produtos nacionais nos processos de licitação, e uma preferência adicional se esses produtos forem resultado de desenvolvimento e inovação tecnológica realizado no país. Publicado no DOU de 16 de dezembro de 2010. Brasília. Distrito Federal.

61. Nardi EP, Ferraz MB, Pinheiro GRC, Kowalski SC, Sato EI. Perceptions of the population regarding generic drugs in Brazil: a nationwide survey. BMC Public Health. 2015;15:117. doi: 10.1186/s12889-015-1475-1

62. Oliveira JC. Monitoramento e vigilância tecnológica do mercado de medicamentos genéricos no Brasil no período de 2000 a 2015. Brasília. 2015. Monografia (Trabalho de Conclusão de Curso). Universidade de Brasília: Curso de Graduação em Saúde Coletiva. Brasília. Distrito Federal. 47 p. 